\title{
Integral Use of Amaranth Starch to Obtain Cyclodextrin Glycosyltransferase, by Bacillus megaterium, to Produce $\beta$-Cyclodextrin
}

\author{
María Belem Arce-Vázquez ${ }^{1}$, Edith Ponce-Alquicira ${ }^{1}$, Ezequiel Delgado-Fornué2, \\ Ruth Pedroza-Islas ${ }^{3}$, Gerardo Díaz-Godínez ${ }^{4 *}$ and J. Soriano-Santos ${ }^{1 *}$ \\ ${ }^{1}$ Department of Biotechnology, Metropolitan Autonomus University, Mexico, Mexico, ${ }^{2}$ Department of Wood, Cellulose and \\ Paper, Biomaterials Research Center, University of Guadalajara, Jalisco, Mexico, ${ }^{3}$ Department of Engineering and Chemistry, \\ Iberoamericana University, Mexico, Mexico, ${ }^{4}$ Laboratory of Biotechnology, Research Center for Biological Sciences, \\ Autonomous University of Tlaxcala, Tlaxcala, México
}

OPEN ACCESS

Edited by:

Bhim Pratap Singh, Mizoram University, India

Reviewed by: Ram Prasad, Amity University, India Mukesh Kumar Yadav, Korea University, South Korea

*Correspondence: Gerardo Díaz-Godínez diazgdo@hotmail.com

J. Soriano-Santos

jss@xanum.uam.mx

Specialty section:

This article was submitted to Microbiotechnology, Ecotoxicology and Bioremediation,

a section of the journal

Frontiers in Microbiology

Received: 18 July 2016 Accepted: 09 September 2016 Published: 23 September 2016

Citation:

Arce-Vázquez MB, Ponce-Alquicira E, Delgado-Fornué E, Pedroza-Islas $R$, Díaz-Godínez $G$ and Soriano-Santos J (2016) Integral Use of Amaranth Starch to Obtain Cyclodextrin Glycosyltransferase, by Bacillus megaterium, to Produce $\beta$-Cyclodextrin

Front. Microbiol. 7:1513.

doi: 10.3389/fmicb.2016.01513
Cyclodextrin glycosyltransferase (CGTase) is an enzyme that produces cyclodextrins (CDs) from starch and related carbohydrates, producing a mixture of $\alpha^{-}, \beta-$, and $\gamma$-CDs in different amounts. CGTase production, mainly by Bacillus sp., depends on fermentation conditions such as $\mathrm{pH}$, temperature, concentration of nutrients, carbon and nitrogen sources, among others. Bacillus megaterium CGTase produces those three types of CDs, however, $\beta-C D$ should prevail. Although, waxy corn starch (CS) is used industrially to obtain CGTase and CDs because of its high amylopectin content, alternative sources such as amaranth starch (AS) could be used to accomplish those purposes. AS has high susceptibility to the amylolytic activity of CGTase because of its $80 \%$ amylopectin content. Therefore, the aim of this work was evaluate the AS as carbon source for CGTase production by $B$. megaterium in a submerged fermentation. Afterwards, the CGTase was purified partially and its activity to synthesize $\alpha-, \beta$-, and $\gamma$-CDs was evaluated using $1 \%$ AS as substrate. B. megaterium produced a $66 \mathrm{kDa}$ CGTase (Topt $=50^{\circ} \mathrm{C}$; pHopt $=8.0$ ), from the early exponential growth phase which lasted $36 \mathrm{~h}$. The maximum CGTase specific activity (106.62 $\pm 8.33 \mathrm{U} / \mathrm{mg}$ protein) was obtained after $36 \mathrm{~h}$ of culture. CGTase obtained with a $\mathrm{Km}=0.152 \mathrm{mM}$ and a $\mathrm{Vmax}=13.4 \mu \mathrm{M} / \mathrm{min}$ yielded $40.47 \%$ total $\mathrm{CDs}$ using AS which was roughly twice as much as that of corn starch (CS; 24.48\%). High costs to produce CDs in the pharmaceutical and food industries might be reduced by using AS because of its higher $\alpha^{-}, \beta$ - and $\gamma$-CDs production (12.81, 17.94 , and $9.92 \%$, respectively) in a shorter time than that needed for CS.

Keywords: amaranth starch, CGTase, cyclodextrin, submerged fermentation, Bacillus megaterium

\section{INTRODUCTION}

Cyclodextrins (CDs) are synthesized from starch and related carbohydrates such as amylose, amylopectin and maltooligosaccharide by cyclodextrin glycosyltransferase (CGTase, E.C.2.4.1.19) which is a bacterial extracellular enzyme (Ahmed and El-Refai, 2010). CGTase catalyzes the CDs formation from starch via inter- and intramolecular transglycosylation reactions, which include 
cycization, disproportionation, coupling, and hydrolysis. CGTases usually produce a mixture of CDs, glucose, maltose, and other oligosaccharides with varying polymerisation degrees. The main natural CDs are $\alpha-, \beta-$, and $\gamma$-CDs containing 6,7 , and 8 glucopyranose units, respectively. CDs have a unique structure of hydrophobic cavity of different diameter smaller than $0.6,0.8$, and $1.0 \mathrm{~nm}$, respectively and hydrophylic surface. Furthermore, CDs are typical host molecules and may encapsulate a great variety of molecules to form crystalline inclusion complexes. The size/shape relationship and hydrogen bond interactions are vital for stability of the guest/host inclusion complex (Anselmi et al., 2008). Thus, the formation of the inclusion complexes modifies the physical and chemical properties of the host molecule, mostly in terms of water solubility. In this sense, CDs are important ingredients as molecular encapsulators for applications in food, cosmetic, and pharmaceutical industries (Sivakumar and Shakilabanu, 2013). For instance, topical application of ferulic acid (FA) may be useful for preventing skin cancer, but its application on the skin is limited by the poor stability of FA. The problem may be overcome by the use of CDs to form stable inclusion complexes to increase the stability of the active principle, and improve its solubility, bioavailability and delivery on the skin. Due to the importance of CDs and the derivatives, their safety and toxicological profiles have been reviewed. Oral administration of $\alpha-C D$ is, in general, well tolerated and is not associated with significant adverse effects. $\alpha-C D$ is not metabolized in the upper intestinal tract and its cleavage is only due to the intestinal flora of cecum and colon. $\beta$-CD has low aqueous solubility and side effects (e.g., nephrotoxicity), for this reason can be used orally because by this route is normally non-toxic. $\beta$-CD binds cholesterol, is absorbed in small scale $(1-2 \%)$ in the upper intestinal tract after oral administration, and is less irritating than $\alpha-C D$ after intramuscular injection. $\beta-C D$ is the most commonly used CD in pharmaceutical formulations, and thus, it is probably the most studied in humans. Comparing the toxicological profile of the three natural CDs, $\gamma$-CD seems to be the least toxic. But its complexes normally have limited solubility in aqueous solutions and tend to self-aggregate; therefore, its complexing abilities are limited compared to those of $\beta$-CD and some water-soluble $\beta$-CD derivatives (Sá Couto et al., 2015). A comparative analysis of more than 30 currently known CD containing pharmaceutical formulations shows that $\beta$-CD is the most commonly employed. The reason for this lies in the ease of its production and subsequent low price (more than 10,000 tons produced annually with an average bulk price of approximately $5 \mathrm{USD}$ per $\mathrm{kg}$ ). However, $\beta$-CD has some drawbacks, mainly its relatively poor aqueous solubility. Due to its, $\beta$-CD is unsuitable for parenteral administration. A universal solution to this problem was found in the substitution of multiple $\beta$-CD hydroxyls on both rims of the molecule resulting in a notably improved aqueous solubility (Kurkov and Loftsson, 2013).

CGTase is produced by bacteria, which can be found in various places such as soil, waste plantation, hot springs and even in deep sea mud. These bacteria are mostly Bacillus sp. However, Klebsiella pneumoniae, Micrococcus luteus, Thermococcus sp., Brevibacterium sp. and hyperthermophilic archaea are also reported as CGTase producers. The bacterial strain Bacillus macerans is the most frequently used source of the CGTase enzyme, but $B$. megaterium isolated from soil has also been utilized to optimize the CGTase production (Sivakumar and Shakilabanu, 2013). CGTase produced by B. megaterium, forms all three types of CDs, but the predominant product is $\beta$ CD (Pishtiyski et al., 2008). During the past 2 decades, 51 different CGTase crystal structures, isolated from bacteria, have been published. The 3D structures of CGTases from these sources are quite similar $(>60 \%)$. According to the different CD specificities. $\alpha$-, $\beta$-, or $\gamma$-CDs; CGTases are usually clasified into 3 subgroups ( $\alpha$-, $\beta$-, and $\gamma$-CGTases), which often have different CD specificities. Paenibacillus macerans, Bacillus circulans, Alkaliphillic Bacillus sp. and Bacillus agaradhaerens are commonly used to produce $\beta-C D$, because of it is catalyzed by a $\beta$-CGTase. Production of CGTase by $B$. megaterium and its optimized parameters are known, however, all CGTases produce $\alpha-, \beta$-, and $\gamma$-CDs from starch in different ratios depending on the nature of CGTase and the reaction conditions (Han et al., 2014). Therefore, this study was also conducted to know the specificity of CGTase from B. megaterium as well as the CDs ratio that produced using amaranth starch (AS) as an alternative carbon source. Other strategy could be that used by Zhou et al. (2012), where they produce a recombinant $\alpha$-CGTase by adapting its original $\alpha$-CGTase gene to the codon usage of $B$. megaterium by systematic codon optimization. CGTase production can be improved by manipulating fermentation conditions such as $\mathrm{pH}$, temperature, concentrations of nutrients and compositions of the production media (carbon and nitrogen sources). Sivakumar and Shakilabanu (2013) found that maltose was the best carbon source and yeast extract was the best nitrogen source for CGTase production using B. megaterium. Moreover, $\mathrm{Ca}^{2+}$ also influences the enzyme production. Optimization of culture conditions of CGTase production by $B$. megaterium NCR has been reported by Ahmed and El-Refai (2010). They found that fermentation time and $\mathrm{K}_{2} \mathrm{HPO}_{4}$ level were crucial factors in order to improve enzyme production process. Recently, the continuous operation has been chosen over the batch system, because it offers a greater process control, high productivity and an improvement of quality and yield. Thus, Rakmai and Cheirsilp (2016) have informed about a continuous production of $\beta$-CD by immobilized CGTase in mixed gel beads performed in a continuous stirred tank reactor and a packed bed reactor. Soluble corn starch (CS) has commonly been used as the substrate for CGTase production. Molecules of amylose and amilopectin (starch fractions) are organized into quasicrystalline macromolecular aggregates called starch granules. The size, shape, and structure of these granules vary substantially among botanical sources. The proportion of amylose and amylopectin in starches also vary with their source, but they usually fall in the range of $20-30 \%$ of amylose in normal cereral starch. Various types of starch can be used as substrate for CDs production, such as starch of potato and tapioca among others. Amylopectin gives higher yield of CDs because the reaction with CGTase begins at the non-reducing end of this branched molecule. Many efforts have been made to improve the production of CDs. For instance, to determine the optimal condition for $\beta-\mathrm{CD}$ production, it is essential 
to understand the kinetics of the reaction. Until now, there have been several reports on factors affecting CD production by CGTases from several microorganisms. Some reports have focused on the kinetics of CGTase, but most of them have only focused on the effect of substrate concentation. The $\beta$-CD production by different sources of CGTase leads to a change in the kinetic behavior with impact on yield and productivity. The source of starch affect temperature for gelatinization, substrate concentration, enzyme concentration and reaction temperature on kinetics of $\beta$-CD production by CGTase (Cheirsilp et al., 2010).

Amaranth is a pseudo-cereal consumed mainly in Mexico and in Central and South America. Its starch content is around 58$66 \%$ and contain lysine at similar level to that of milk casein. AS is of a waxy or glutinous kind and consists of spherical, angular or poligonal granules with an exceptionally small size, ranging from 0.5 to $3 \mu \mathrm{m}$ in diameter, which gives it high dispersibility. Amylose content in amaranth starch is exceptionally low, in the range $0-14 \%$. Therefore, amaranth starch granules have high susceptibility to amylases because of their exceptionally high amylopectin content (Kong et al., 2009). Urban et al. (2012) used starch from Amaranthus cruentus to produce $\alpha$-, $\beta$-, and $\gamma$-CDs by CGTase from Paenibacillus macerans CCM 2012. CGTase was obtained using soluble corn starch as substrate, by a 3-day cultivation in submerged fermentation $(\mathrm{SmF})$ under aerobic conditions. However, the growth kinetic parameters of bacteria and enzyme activity at fermentation conditions were not evaluated. Hence, production of CGTase using AS as carbon source has not been assessed yet. Therefore, the aim of this work was, in the first part of the study, to characterize the CGTase production by B. megaterium in a SmF using starch of Amaranthus hypochondriacus L. as carbon source and CS was used as comparation. In the second part, CGTase obtained was used for study the production of CDs.

\section{MATERIALS AND METHODS}

\section{Amaranth Starch}

Grain of Amaranthus hypochondriacus L. of cultivar Revancha obtained from INIFAP-Campus Montecillo, Mexico was used in this research. Starch isolation from the amaranth grain was made by the alkaline method described by Villarreal et al. (2013). Briefly, the whole grain was milled using a Udy mil (Udy Corporation Fort Collins, Co, USA) until a flour was obtained. Flour (25 g) was steeped in a $1 \mathrm{~N} \mathrm{NaOH}(1: 8)$ solution in a magnetic shaking heater at room temperature for $1 \mathrm{~h}$. The mixture was then centrifuged at $3900 \times \mathrm{g}$ in a $420 \mathrm{R}$ Hettich equipment and the supernatant was kept to determine residual proteins. The precipitated solids were re-extracted until the protein content was less than $1 \mathrm{mg} / \mathrm{mL}$. Then they were resuspended in distilled water and adjusted $\mathrm{pH}$ to 7 . Afterwards, they were washed and filtered with distilled water through a 74 $\mu \mathrm{m}$ opening stainless steel mesh. The retained fiber portion was milled, washed and filtered using distilled water. The resulted suspension was centrifuged, the supernatant discarded, as well as, the top layer of scrapped starch dark until an imperceptible dark layer was left. The resulting AS was oven dried at $60^{\circ} \mathrm{C}$ for $12 \mathrm{~h}$ and milled in a mortar and sieved in a $74 \mu \mathrm{m}$ mesh. The moisture, ashes and crude protein of isolated from AS were determined in accordance with the Association of Official Analytical Chemists (AOAC, 2000) standardized techniques. The total starch content was determined by the method described by Holm et al. (1986). The protocol includes solubilizing the sample starch, converting it quantitatively to glucose and assaying the glucose with the glucose oxidase/peroxidase reagent. The glucose content in the sample was computed by least squares linear regression. The starch content was calculated on a dry matter basis according to the following formula:

$$
\begin{aligned}
& \text { \% starch }= \\
& \frac{\mu \mathrm{g} \text { glucose } \times 10^{-3} \times 25^{a)} \times 100(\text { or less })^{a)} \times 0.9^{b)}}{\text { sample weight }(\mathrm{mg} \text { dry basis })} \times 100
\end{aligned}
$$

where:

a) $=$ dilution factors

b) $=$ correction factor (glucose $\rightarrow$ glucan)

The yield and recovery of the starch obtained were estimated according to the following formulae:

$$
\begin{aligned}
\% \text { yield } & =\frac{\text { starch extracted }(g)}{\text { initial sample quantity }(g)} \times 100 \\
\% \text { recovery } & =\frac{\text { starch extracted }(g)}{\text { total starch sample }(g)} \times 100
\end{aligned}
$$

Amylose content was analyzed using an amylose/amylopectin Assay Kit (Megazyme, Ireland) based on concanavalin A (Con A) method. Briefly, starch samples were completely dispersed by heating in dimethyl sulphoxide. Lipids were removed by precipitating the starch in ethanol, recovering the precipitated starch. After dissolution of the precipitated sample in an acetate/salt solution, amylopectin was specifically precipitated by adding Con $\mathrm{A}$ and then it was removed by centrifugation. The amylose was enzymatically hydrolyzed at D-glucose, which was analyzed using glucose oxidase/peroxidase (glucose oxidase plus peroxidase and 4-aminoantipyrine (GOPOD)) reagent. The total starch amount, in a separate aliquot of the acetate/salt solution, was also hydrolyzed at D-glucose and was measured colorimetrically by glucose oxidase/peroxidase. The concentration of amylose in the starch sample was estimated as the ratio of absorbance of GOPOD at $510 \mathrm{~nm}$ of the supernatant of the precipitated sample with Con A, regard to the total starch sample.

The AS used in this study yielded $57.47 \pm 0.28 \%$ with a recovery of $58.70 \pm 0.18 \%$. The proximal chemical analysis of amylaceous extract was (in g/100 g): moisture (8.07 \pm 0.5 ), ashes $(0.10 \pm 0.0)$, and crude protein $(0.06 \pm 0.00)$. The $L * a * b$ color parameters of AS were measured using a Hunter Lab Color Flez EZ (Hunter Lab, USA) iluminante D65, 10 ${ }^{\circ}$, and 125 inch diameter aperture $(\mathrm{L}=96.21 \pm 0.28, \mathrm{a}=0.067 \pm 0.003$ and $\mathrm{b}$ $=1.26 \pm 0.06$ ) being similar to other AS (Villarreal et al., 2013). The starch content of the amylaceous extract was $97.43 \pm 1.54 \%$., which had amylose $(3.99 \pm 0.12 \%)$ and amylopectin $(96.01 \pm$ $0.25 \%$ ) content. These values were very similar to those displayed 
by amylose and amylopectin in A. cruentus (5.4 and 94.6\%, respectively; Kong et al., 2009; Villarreal et al., 2013). CS (total starch content $=99.0 \%$; amylose content $=25.0 \%$; amylopectin content $=75.0 \%$; Sigma, Mexico) was used to compare the yields of CGTase and $\beta$-CD production.

\section{Microorganism and Culture Media}

CGTase was obtained using B. megaterium ATCC-10778. This bacterium was obtained from the strains collection of the School of Chemistry that belongs to the National Autonomous University of Mexico. The strain was spread on an agar plate with a medium that consisted of $(\mathrm{g} / \mathrm{L})$ : meat-peptone broth 12.0, starch 10.0 and agar-agar 20.0. The $\mathrm{pH}$ of the medium was adjusted to 7.5 . Plates were incubated at $37^{\circ} \mathrm{C}$ for $24 \mathrm{~h}$. For inoculum preparation, the biomass from the agar plate was transferred to a $500 \mathrm{~mL}$ Erlenmeyer flask, with $50 \mathrm{~mL}$ of a medium at $\mathrm{pH} 7.0$ that contained $(\mathrm{g} / \mathrm{L})$ : starch 12.0 , dextrose 10.0 and meat-peptone broth 5.0. The strain was cultivated at $37^{\circ} \mathrm{C}$ on a rotary shaker at $200 \mathrm{rpm}$ for $24 \mathrm{~h}$.

\section{Fermentation Conditions for CGTase and Biomass Production}

Biosynthesis of CGTase in SmF was carried out in a $1 \mathrm{~L}$ fermenter with $250 \mathrm{~mL}$ of sterile broth based on that used by Usharani et al. (2014), that contained the following (in g/L): AS (CS as control) (12.0), yeast extract (2.5), peptone (2.5), $\mathrm{KH}_{2} \mathrm{PO}_{4}(2.0), \mathrm{K}_{2} \mathrm{HPO}_{4}$ (1.0) $\mathrm{MgSO}_{4}$ (0.2). The medium was added with $0.5 \%$ (v/v) corn steep liquor. The medium $\mathrm{pH}$ was adjusted to 7.5. The fermenter was inoculated with $9.6 \times 10^{5} \mathrm{UFC}$ of $B$. megaterium. The strain was incubated at $37^{\circ} \mathrm{C}$ at a constant agitation speed of $200 \mathrm{rpm}$ for $96 \mathrm{~h}$. Sample of $3 \mathrm{~mL}$ was taken every $12 \mathrm{~h}$. The cells were centrifuged under cooling at $3500 \times \mathrm{g}$ for $15 \mathrm{~min}$ and in the supernatant, the CGTase activity was evaluated as well as, the content of protein and starch and $\mathrm{pH}$ were determined. Finally, the biomass was determined by dry weight.

Assay of biomass $\mathrm{X}=\mathrm{X}(\mathrm{t})$ was done by using the VelhurstPearl or logistic equation:

$$
\frac{\mathrm{dx}}{\mathrm{dt}}=\mu\left(1-\frac{\mathrm{X}}{\mathrm{X}_{\text {máx }}}\right) \mathrm{X}
$$

Where $\mu$ is the maximal specific growth rate and $X_{\max }$ is the maximal (or equilibrium) biomass level achieved when $\mathrm{dX} / \mathrm{dt}=$ 0 for $\mathrm{X}>0$. The solution of Velhurst-Pearl equation is as follows:

$$
X=\frac{X_{\max }}{1+C e^{-\mu t}}
$$

Where, $\mathrm{C}=\left(\mathrm{X}_{\max }-\mathrm{X}_{0}\right) / \mathrm{X}_{0}$, and $\mathrm{X}=\mathrm{X}_{0}$; the initial biomass value.

The estimation of kinetic parameters in the above equation was performed using a non-linear least square-fitting program "Solver" (Excel, Microsoft). The assessed kinetic parameters were: CGTase productivity $\left(\mathrm{P}_{\mathrm{E}}=\mathrm{E}_{\max } / \mathrm{t}\right)$ was evaluated by using the time of $\mathrm{E}_{\max } . \mathrm{Y}_{\mathrm{E} / \mathrm{X}}$ is the yield of CGTase per unit of biomass produced, estimated as the relation between maximal CGTase activity $\left(\mathrm{E}_{\max }\right)$ and $\mathrm{X}_{\max }$. CGTase productivity per unit of substrate $\left(\mathrm{Y}_{\mathrm{E} / \mathrm{S}}=\mathrm{E}_{\max } / \mathrm{S}\right)$.

\section{CGTase Activity Assay}

The cyclization activity of CGTase was measured according to the phenolphthalein (PHP) method utilized by Costa et al. (2015). The $\beta$-CD production was assessed spectrophotometrically at 550 $\mathrm{nm}$ on the basis of its ability to form a colorless inclusion complex with PHP. Briefly, a reaction mixture of $1 \mathrm{~mL}$ containing $1 \%$ starch in $50 \mathrm{mM}$ Tris- $\mathrm{HCl}$ buffer $(\mathrm{pH} 8)$ and $30 \mu \mathrm{L}$ of crude enzyme were incubated at $40^{\circ} \mathrm{C}$ for $30 \mathrm{~min}$. Then the reaction was stopped by a thermal shock. Afterwards $0.5 \mathrm{ml}$ of reaction mixture was added with $1.2 \mathrm{~mL}$ of $3 \mathrm{mM}$ PHP in $500 \mathrm{mM}$ sodium carbonate buffer, $\mathrm{pH}$ 10.0. The amount of $\beta$-CD was determined by the absorbance decrease at $550 \mathrm{~nm}$. One unit of the CGTase (U) was defined as the amount of enzyme that catalyzes the production of $1 \mu \mathrm{mol}$ of $\beta$-CD per min under the assay conditions. A calibration curve was made using 80 to 800 $\mu \mathrm{M} \beta$-CD. Finally, the specific activity of CGTase was expressed as $\mathrm{U} / \mathrm{mg}$ protein.

The optimum $\mathrm{pH}$ and optimum temperature of CGTase were assessed according to More et al. (2012) with some modifications. A range of different $\mathrm{pH}$ values $(3-10)$ at $40^{\circ} \mathrm{C}$ for $15 \mathrm{~min}$ were assayed by using $0.2 \mathrm{M}$ citrate buffer ( $\mathrm{pH} 3-4), 0.1 \mathrm{M}$ acetate buffer ( $\mathrm{pH}$ 5-6), 0.1 M phosphate buffer ( $\mathrm{pH} 7$ ), $0.05 \mathrm{M}$ Tris$\mathrm{HCl}$ buffer ( $\mathrm{pH}$ 8) and $0.1 \mathrm{M}$ borate-chloride buffer ( $\mathrm{pH} 9-10)$. The aliquots were removed after incubation and assayed for the cyclization activity of CGTase. The effect of temperature on CGTase activity was evaluated in the range of $35-70^{\circ} \mathrm{C}$ in 50 $\mathrm{mM}$ Tris- $\mathrm{HCl}(\mathrm{pH} 8)$ buffer. After incubation for $10 \mathrm{~min}$, the cyclization activity was measured.

\section{Partial Purification of CGTase Enzyme}

The isolation of the CGTase was performed according to a previous method described by Gheetha and More (2010), with minor modifications. In the crude extract ( $\mathrm{SmF}$ supernatant obtained after $36 \mathrm{~h}$ of culture), the fractional precipitation was performed by using ammonium sulfate (50, 75, and $80 \% \mathrm{w} / \mathrm{v})$; then the enzyme was collected by centrifugation at $4000 \times \mathrm{g}$ for $20 \mathrm{~min}$ at $4{ }^{\circ} \mathrm{C}$. The precipitated protein was re-dissolved in $5 \mathrm{mM}$ Tris- $\mathrm{HCl}$ buffer $(\mathrm{pH} 8.0)$. Then the precipitated residue was dialyzed using a membrane with a cut size of 68000 (Spectra / Por ${ }^{\circledR}$ Dialysis) against distilled water for $16 \mathrm{~h}$. Afterwards, the water was changed every $2 \mathrm{~h}$. Then $200 \mu \mathrm{l}$ of enzyme crude was loaded onto a Sephadex G-200 column (1.4 $\times 29 \mathrm{~cm}$ ) (Pharmacia, Uppsala, Sweden) using a Pharmacia LKB FPLC System (Uppsala, Sweden). The proteins were eluted by using the previous buffer at $0.2 \mathrm{~mL} / \mathrm{min}$. The $2 \mathrm{~mL}$ fractions were collected and monitored at $280 \mathrm{~nm}$. The fractions with maximum absorbance were pooled and concentrated using a Sephadex G-50 column, equilibrated with $5 \mathrm{mM}$ Tris- $\mathrm{HCl}$ buffer ( $\mathrm{pH} 8.0)$. Then the fractions $(2 \mathrm{~mL})$ were collected in order to assess the enzymatic activity. The partially purified CGTase was confirmed by using a sodium dodecyl sulfate poly-acrylamide gel electrophoresis (SDS-PAGE). A protein molecular weight marker (Bio-Rad, Hercules, CA., USA) was used with the following: myosin $200 \mathrm{kDa} ; \beta$-galactosidase $116.25 \mathrm{kDa}$; phosphorylase $\mathrm{b}$ $97.4 \mathrm{kDa}$; serum albumin $66.2 \mathrm{kDa}$; ovalbumin $45 \mathrm{kDa}$; carbonic anhydrase $31 \mathrm{kDa}$; trypsin inhibitor $21.5 \mathrm{kDa}$, lysozyme $14.4 \mathrm{kDa}$ and aprotinin $6.5 \mathrm{kDa}$. 


\section{CGTase Kinetic Parameters}

The parameters of CGTase were assessed through a MichaelisMenten equation and the double reciprocal plot method by Lineweaver-Burk. Km and Vmax were determined with 10-100 $\mathrm{mg} / \mathrm{mL}$ of AS in $50 \mathrm{mM}$ Tris- $\mathrm{HCl}$ buffer $(\mathrm{pH} 8)$ at $50^{\circ} \mathrm{C}$ for up to $30 \mathrm{~min}$. After incubation of the mixture reaction, the cyclization activity of CGTase was measured.

\section{Production}

The native AS isolated from grain of A. hypochondriacus L. was used to obtain $\beta$-CDs. Corn starch (CS) was also used as a positive control of the trial. The method carried out by Ibrahim et al. (2011), with some modifications, was used for the CDs formation. Briefly, starch gelatinization was performed at 50 and $70^{\circ} \mathrm{C}$ (for AS and CS, respectively) for $10 \mathrm{~min}$ in $50 \mathrm{mM}$ glycine buffer ( $\mathrm{pH} \mathrm{8);} \mathrm{then} \mathrm{the} \mathrm{reaction} \mathrm{mixture} \mathrm{was} \mathrm{cooled} \mathrm{to} \mathrm{room}$ temperature. Afterwards, CGTase partially purified $(39 \mathrm{U} / \mathrm{mL})$, previously obtained using AS as carbon source for B. megaterium, was reacted with $1 \%(\mathrm{w} / \mathrm{v})$ substrate in glycine- $\mathrm{NaOH}$ buffer $(\mathrm{pH}$ 8 ) at $50^{\circ} \mathrm{C}$ for $12 \mathrm{~h}$. The enzymatic reaction was stopped by boiling it for $10 \mathrm{~min}$ and after that, the reaction mixture was submerged in cold water for $10 \mathrm{~min}$.

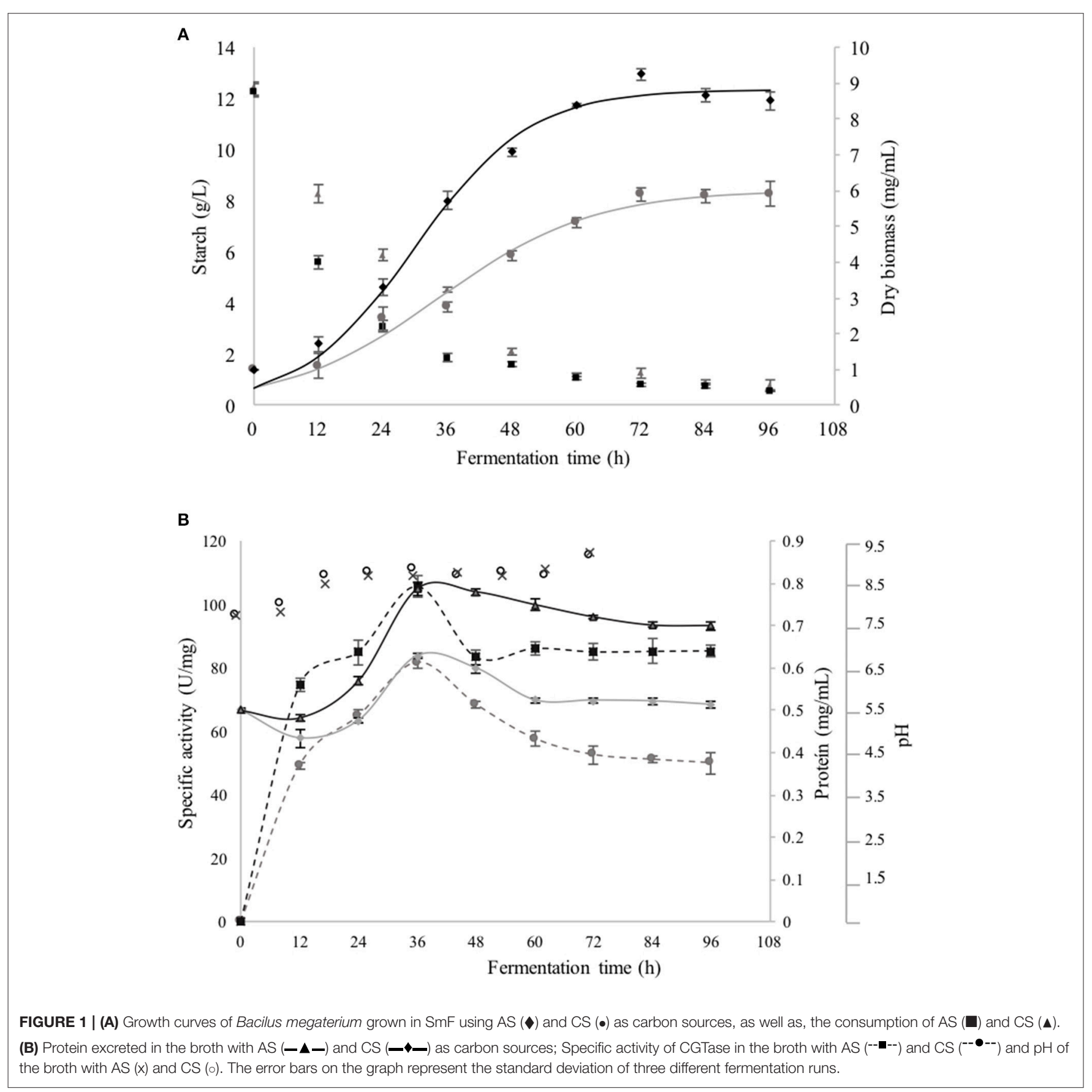


The CDs produced were measured by mass spectrometry (MS). The following settings were used: electrospray ionization (ESI) in positive mode. The dry gas (nitrogen) flow rate was set at $4.0 \mathrm{~L} / \mathrm{min}$ and the dry heater operated at $180^{\circ} \mathrm{C}$. The capillary voltage was set at $4500 \mathrm{~V}$ and the end plate offset at $-500 \mathrm{~V}$. Collision energy varied in the range of $25-30 \mathrm{eV}$. All ESI-MS experiments were performed on a MicrOTOFQII mass spectrometer equipped with an electrospray ion source (Bruker-Daltonics, Bremen, Germany). MS data were recorded in full scan mode (from 50 to $3000 \mathrm{~m} / \mathrm{z}$ ). Data processing was carried out with Chromeleon 6.8. Next the samples were introduced directly to the electrospray source of the MS using an LC pump and the mobile phase at a flow rate $3.0 \mu \mathrm{L} / \mathrm{min}$. The mobile phase consisted of $\mathrm{H}_{2} \mathrm{O} / \mathrm{ACN} / \mathrm{FA}(90: 10: 0.1, \mathrm{v} / \mathrm{v} / \mathrm{v})$ (A) and $\mathrm{MeOH} / \mathrm{ACN} / \mathrm{FA}(90: 10: 0.1, \mathrm{v} / \mathrm{v} / \mathrm{v})$ (B) in an A:B ratio of 90:10, v/v. HRMS (high resolution) measurements provided by a TOF analyzer in order to enable the processing of the elemental composition of the registered ions. The percentage of starch conversion (\%) was defined as the weight percentage of initial substrate converted into total CDs ( $\mathrm{g} \beta-\mathrm{CD} / 100 \mathrm{~g}$ starch).

\section{Statistical Analysis}

All experimental results were analyzed by one-way analysis of variance (ANOVA) and the Tukey's multiple comparison test ( $p$ $<0.05)$.

\section{RESULTS}

\section{Growth Parameters of the B. megaterium Strain for CGTase Production}

The kinetic growth parameters of B. megaterium in the SmF are presented in Figures 1A,B. Lag phase was practically negligible; the total growth time of $B$. megaterium was of 4 days (Figure 1A), the exponential phase was shorter when AS was used as substrate (36 h) compared to that observed with CS, which lasted $48 \mathrm{~h}$. The value was significantly greater $(p<0.05)$ when AS was used as carbon source $\left(\mu=0.094 \pm 0.001 \mathrm{~h}^{-1}\right)$ than that with CS (Table 1). After $72 \mathrm{~h}$ of fermentation, AS and CS contents were practically negligible $(p<0.05)$. Values of $\mathrm{pH}$ were very similar between cultures (initial $\mathrm{pH}$ was 7.5 in both cases and with the time rose to 8.5 for the first $24 \mathrm{~h}$. It remained stable until $84 \mathrm{~h}$ of fermentation and finally reached $\mathrm{pH} 9.0$ at the end) (Figure 1B). The time course production of CGTase in relation to the growth phases of B. megaterium is shown in Figures 1A,B. The enzyme synthesis using AS and CS as carbon source, began at the early exponential phase and the maximum CGTase specific activity was obtained after $36 \mathrm{~h}$ of cultivation, with spontaneous increase in cell biomass yield (Figure 1A). Thereafter, the CGTase activity gradually decreased with the prolongation of the fermentation periods up to $96 \mathrm{~h}$. The shape of the curve of extracelular proteins was identical with that of CGTase specific activity. This activity obtained during the SmF, when AS was used at any time of the exponential phase, was roughly $25 \%$ greater than that observed when CS was utilized (Figure 1B). The maximum specific activity of CGTase obtained with AS as carbon source was higher (105.72 $\pm 8.33 \mathrm{U} / \mathrm{mg}$ protein) than that reported with CS (81.75 \pm $3.2 \mathrm{U} / \mathrm{mg}$ protein).
TABLE 1 | Growth kinetic parameters of Bacillus megaterium in SmF for CGTase production.

\begin{tabular}{lcccc}
\hline $\begin{array}{l}\text { Carbon } \\
\text { source }\end{array}$ & $\mu\left(\mathbf{h}^{-1}\right)$ & $\begin{array}{c}\mathbf{Y}_{\mathbf{X} / \mathbf{S}} \\
(\mathbf{g X / g S})\end{array}$ & $\begin{array}{c}\mathbf{Y}_{\mathrm{E} / \mathbf{X}} \\
(\mathbf{U} / \mathbf{g X})\end{array}$ & $\begin{array}{c}\mathbf{Y}_{\mathbf{E} / \mathbf{S}} \\
(\mathbf{U} / \mathbf{g S})\end{array}$ \\
\hline AS & $0.094 \pm 2.3 \times 10^{-3 \mathrm{a}}$ & $11.47^{\mathrm{a}}$ & $9775^{\mathrm{a}}$ & $44602^{\mathrm{a}}$ \\
CS & $0.075 \pm 4.4 \times 10^{-3 \mathrm{~b}}$ & $4.66^{\mathrm{b}}$ & $8689^{\mathrm{a}}$ & $11355^{\mathrm{b}}$ \\
\hline
\end{tabular}

${ }^{a}$ Data are the mean \pm standard deviation of three replicates.

${ }^{b}$ Values that have the same superscript in a column do not differ significantly $(p<0.05)$.

Table 1 shows that when AS was used as carbon source, the biomass and the CGTase, both reported per $\mathrm{g}$ of biomass were

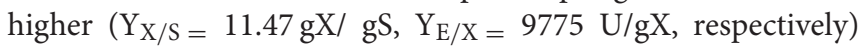
than those reported when was used the CS under the same fermentation conditions. The CGTase activity reported per $\mathrm{g}$ of AS was three times higher $\left(\mathrm{Y}_{\mathrm{E} / \mathrm{S}}=44602 \mathrm{U} / \mathrm{g} \mathrm{S}\right)$ that the obtained per $\mathrm{g}$ of $\mathrm{CS}\left(\mathrm{Y}_{\mathrm{E} / \mathrm{S}}=11355 \mathrm{U} / \mathrm{g} \mathrm{S}\right)$. This proves that AS is a good alternative carbon source to obtain a higher yield of CGTase.

\section{CGTase Characterization}

The active fraction used for the biochemical characterization of the enzyme was located between fractions number 23 and 30 obtained from the gel filtration Sephadex G-200 column (Figure 2A). These fractions were gathered, concentrated by ultrafiltration and loaded on a Sephadex G-50 column. The fractions between 10 and 30 displayed CGTase activity (Figure 2B). The enzyme could be sufficiently purified in two steps (Table 2) with a recovery of $10.25 \%$ of activity and 40.32 fold purification for the specific enzymatic activity of $3946 \mathrm{U} / \mathrm{mg}$. SDS-PAGE gel electrophoresis showed the presence of a single protein with an apparent molecular weight $(\mathrm{Mr})$ ca $66 \mathrm{kDa}$ (Figure 2C) accompanied by some minor proteins. The CGTase activity was measured at $40^{\circ} \mathrm{C}$ using the standard assay method by varying the $\mathrm{pH}$ values from 3.0 to 10.0 . The optimum $\mathrm{pH}$ of the purified CGTase was 8.0 (Figure 3A) for the enzyme produced using both AS and CS. Figure $3 \mathrm{~A}$ shows that the CGTase retained its activity at $\mathrm{pHs}$ between 3.0 and 10.0. At pHs 5.0 and 9.0, the retained enzymic activity was in the range of $70 \%$. CGTase activity decreased drastically below these $\mathrm{pH}$ values. The optimum temperature was $50^{\circ} \mathrm{C}$ using $\mathrm{AS}$ and CS as substrate (Figure 3B). Thereafter, the enzymatic activity diminished $60 \%$ with values above $50^{\circ} \mathrm{C}$ and $40 \%$ under this temperature.

\section{Kinetic Characterization}

The Km, Vmax and Kcat values for partially purified CGTase with AS as substrate were $0.152 \mathrm{mM}, 13.4 \mu \mathrm{M} / \mathrm{min}$ and $0.36 \times 10^{-3} / \mathrm{s}$, respectively (Figure $3 \mathrm{C}$ ).

\section{Cyclodextrin Production}

AS was used to synthesize $\beta-C D$ using a partially purified CGTase obtained previously by $B$. megaterium in a SmF. The comparison of the CDs yields from the AS and CS of the chromatographic assays are shown in Table 3. It can be observed that total CDs content obtained with AS was 
A

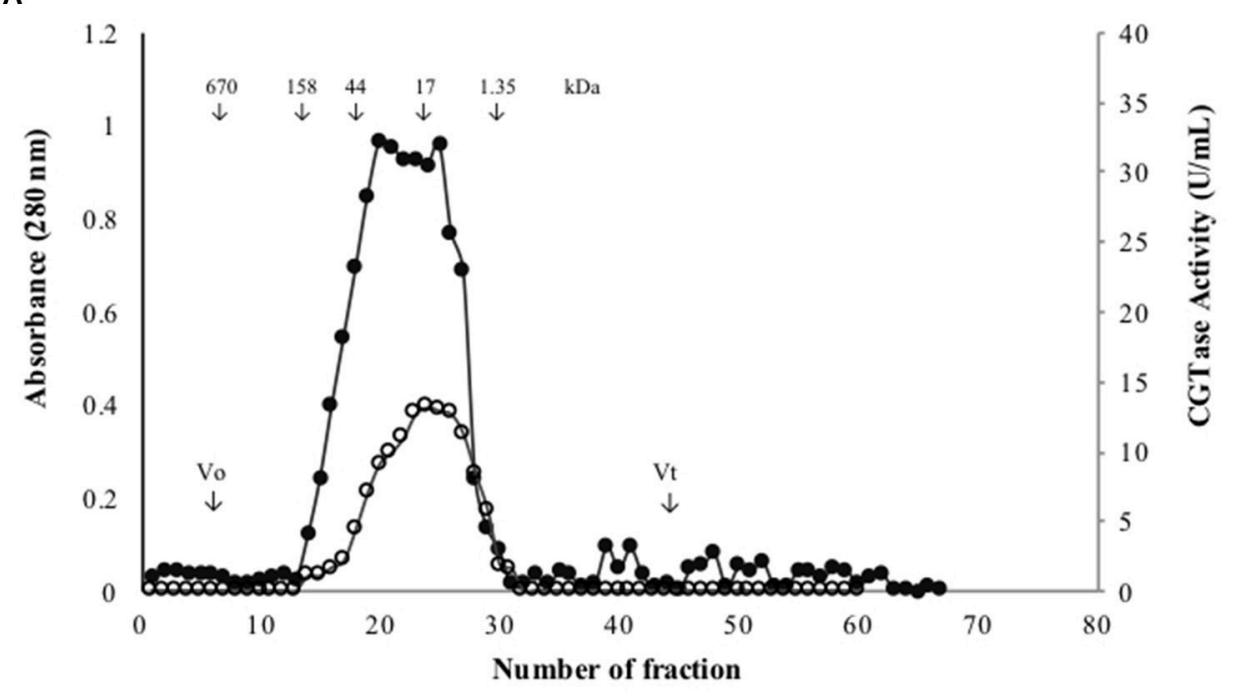

B

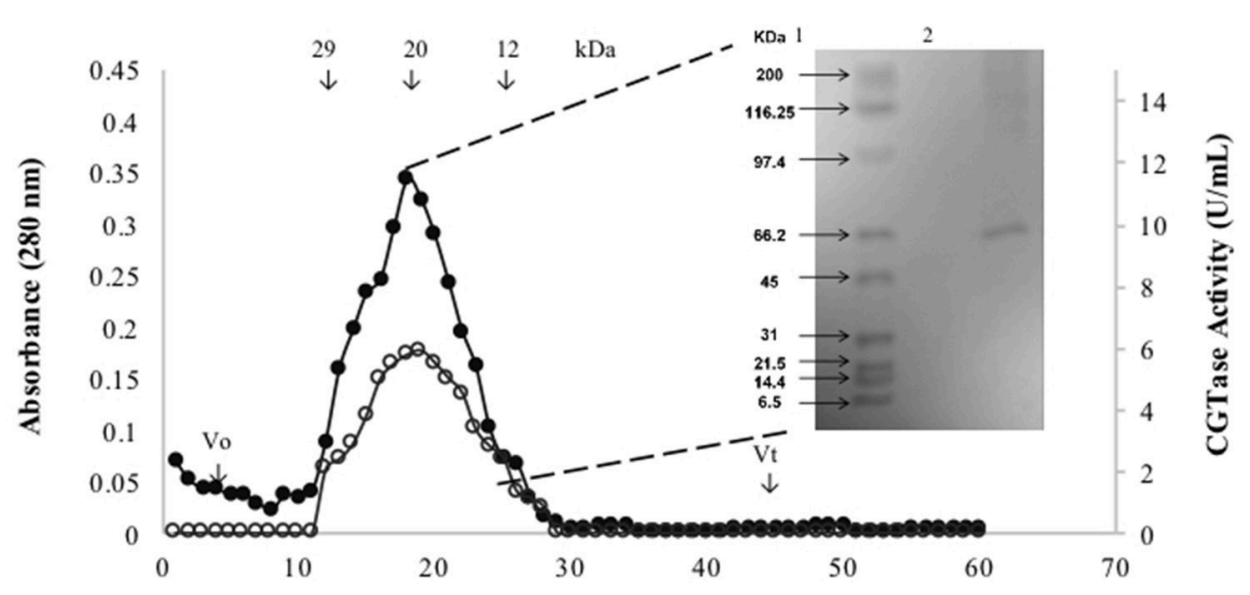

Number of fraction

FIGURE 2 | Gel filtration profiles when was used the culture broth of Bacillus megaterium grown in SmF when AS was used as substrate. (A) Fractions eluted through Sephadex G-200 column (•) and their CGTase activity (०). (B) Fractions eluted through Sephadex G-50 column (•) and their CGTase activity (०). (C) Mr of partially purified CGTase by SDS-PAGE; lane 1, Standard markers; lane 2, partially purified CGTase.

TABLE 2 | Purification summary of an CGTase produced by Bacillus megaterium in SmF using AS as carbon source.

\begin{tabular}{|c|c|c|c|c|c|}
\hline Purification step & Cyclization activity (U/mL) & Protein $(\mathbf{m g} / \mathrm{mL})$ & Specific activity (U/mg) & Yield (\%) & Purification fold \\
\hline Supernatant & $57.75 \pm 3.3$ & $0.59 \pm 0.010$ & 97.88 & 100 & 1.00 \\
\hline $85 \%\left(\mathrm{NH}_{4}\right)_{2} \mathrm{SO}_{4}$ precipitation /dialysis & $29.7 \pm 1.5$ & $0.13 \pm 0.010$ & 228.46 & 51.43 & 2.33 \\
\hline Sephadex G-200 & $13.18 \pm 0.94$ & $0.02 \pm 0.008$ & 659.00 & 22.82 & 6.73 \\
\hline Sephadex G-50 & $5.92 \pm 0.41$ & $0.0015 \pm 0.0001$ & 3946.00 & 10.25 & 40.32 \\
\hline
\end{tabular}

Data are the mean \pm standard deviation of three replicates.

higher $(40.73 \%)$ than that measured for CS $(24.48 \%)$. There are also differences in the distribution of the individual CDs. Higher relative proportions of $\alpha-C D$ and $\beta-C D$ were obtained regardless of the CGTase and starch sources employed (Table 3).

\section{DISCUSSION}

Recently, it has been reported in some works on production of CGTase in SmF that the lag phase was practically negligible as in this study (Costa et al., 2015; Elbaz et al., 2015). Some authors, 


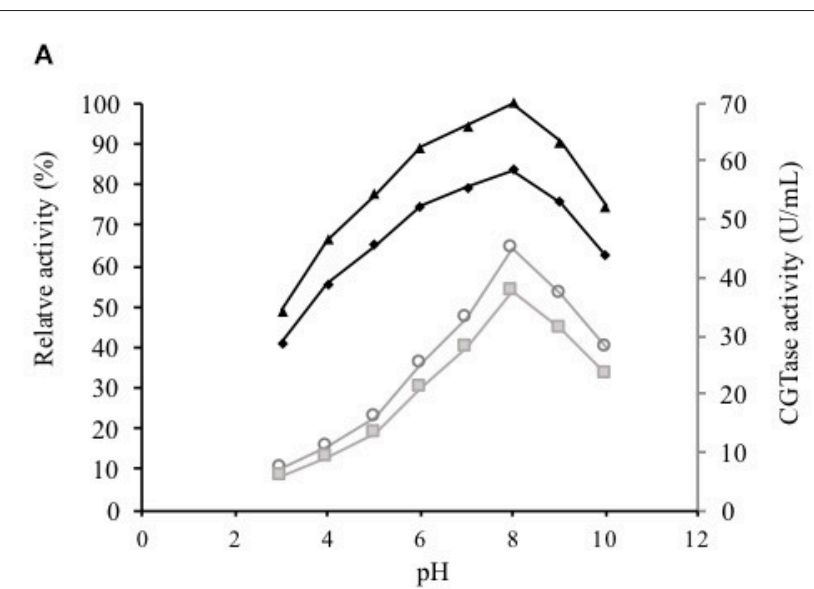

B

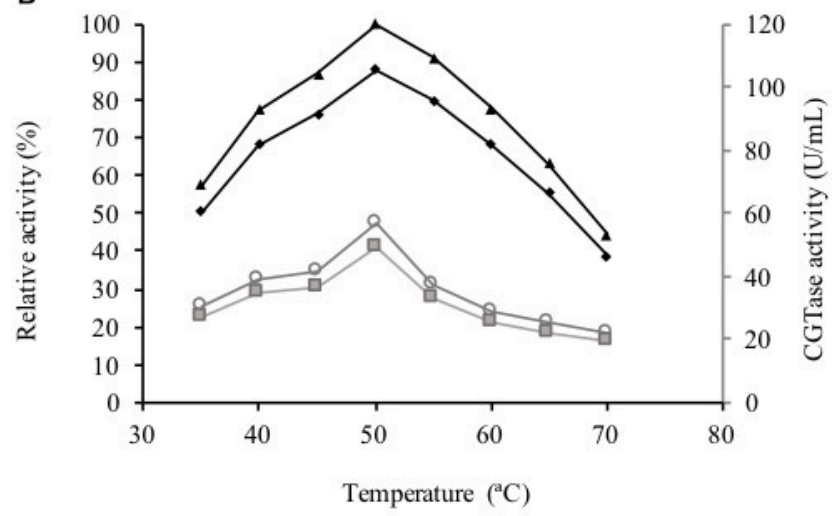

C

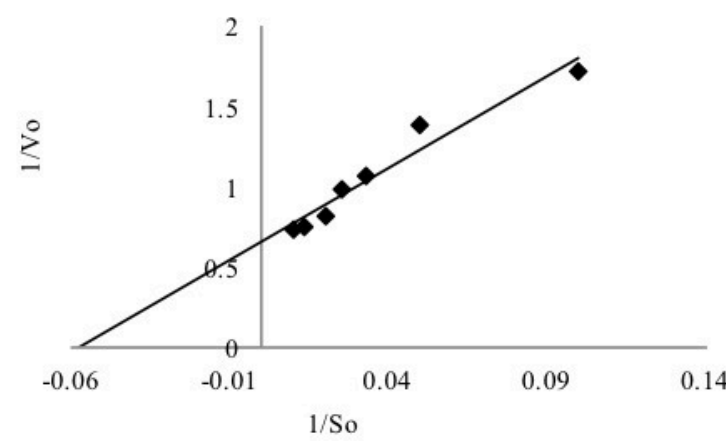

FIGURE 3 | Kinetic curves of the partially purified CGTase. (A) Effect of $\mathrm{pH}$ on the CGTase activity of the enzyme obtained from the broth whit AS ( $)$

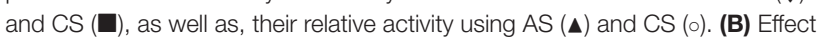
of temperature on the CGTase activity of enzyme obtained from the broth whit

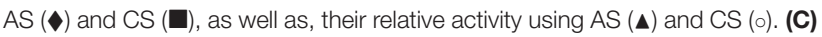
Lineweaver-Burk plot of partially purified CGTase.

however, have found that it is typical for some alkalophilic bacteria, such as Bacillus cirulans var. alkalophilus, to have long lag phases, even lasting 30-34 h (Mäkelä et al., 1990). The increase of $\mathrm{pH}$ of the culture medium observed in the fermentations using both AS and CS as carbon sources, can be partially explained because the excreted proteins can increase during the first hours of fermentation. These proteins can act as buffers and keep $\mathrm{pH}$ levels for up to $60 \mathrm{~h}$. After this time, the gradual increase of $\mathrm{pH}$ until 9.0 can be ascribed to the occurrence of peptides produced by protein hydrolysis as a result of cell desintegration (Mäkelä et al., 1990). Sukiminderjit et al. (2014) reported that the optimum $\mathrm{pH}$ of the CGTase produced by B. megaterium is roughly 8.0. This $\mathrm{pH}$ in a fermentation medium might be beneficial for the enzymatic activity, which is measured by starch cyclization when the reaction occurs with the starch in the culture medium (Ng et al., 2013).

On the other hand, enzyme production can be improved by manipulating fermentation conditions such as $\mathrm{pH}$, temperature, concentrations of nutrients and compositions of the production media (carbon and nitrogen sources). Thus, fermentation conditions may change CGTase yield. Additionally, researchers have been reported recent advances in heterologous expression strategies for improving CGTase production and molecular engineering approaches for enhancing the catalytic properties of CGTases for effective application (Han et al., 2014). It is important to mention that the kinetic growth parameters of $B$. megaterium using AS as substrate in any cultivation conditions have not been previously reported. Mäkelä et al. (1990) observed that CGTase activity appeared in the cultivation broth early in the exponential growth phase, attaining about $65 \%$ of the final value at the beginning of the stationary growth phase and during this growth phase, about $20 \%$ of the final CGTase activity appeared in the medium as a result of cell desintegration or excretion of CGTase by spore-forming cells. In the death phase, CGTase activity still increased slightly. Costa et al. (2015) claimed that a strain of Bacillus cirulans requires the absence of glucose and the presence of starch as carbon source to grow and express the CGTase gene.

The most nutrient-rich culture media increased growth of the strain, but not increased the synthesis of CGTase. Some studies, such as those conducted by de Freitas et al. (2004), have reported the effect of the carbon source on the enzyme synthesis after $48 \mathrm{~h}$ of fermentation. According to their results, Bacillus alkalophilic CGH grew very well with higher CGTase specific activities using starch and maltodextrins as carbon sources. Enzyme production was not observed when glucose was added to the medium. Kitahata et al. (1974) reported a CGTase from Bacillus sp. that was purified by five steps. The enzyme was 43 -fold purified and displayed about $10 \%$ its activity. Both values were very similar to those obtained in this study. On the other hand, Ibrahim et al. (2011) reported that the CGTase from B. agaradhaerens was purified in three steps, with a recovery of $26 \%$ and twice as much specific activity when compared to that observed in this study. After 3 months, the purified CGTase stored at $-4^{\circ} \mathrm{C}$ kept $85 \%$ of its biological activity. Covalent immobilization of CGTase on magnetic particles beads promoted a high stabilization of the CGTase against temperature and $\mathrm{pH}$. For example, this technique retained $90 \%$ of its initial activity when incubated for $1 \mathrm{~h}$ at $\mathrm{pH}$ 9.0 and $50^{\circ} \mathrm{C}$. The same preparation preserved its high catalytic activity after long-term storage at $4^{\circ} \mathrm{C}$ (60 days, 80\%; Ivanova, 2010).

The CGTase shows a Mr similar to other CGTases such as the produced in SmF by Bacillus sp. $(69 \mathrm{kDa})$ and B. firmus $(80 \mathrm{kDa})$ using CS as carbon source (Suntinanalert et al., 1997; Pishtiyski et al., 2008; Savergave et al., 2008; Ibrahim et al., 2011). However, there are some reports on CGTases with different Mr, such as that of Paenibacillus macerans grown with CS where its $\mathrm{Mr}$ 
TABLE 3 | CDs yield produced by a partially purified CGTase obtained by $B$. megaterium in SmF using AS as carbon source and compared to that obtained by Urban et al. (2012).

\begin{tabular}{|c|c|c|c|c|c|c|c|c|}
\hline & \multicolumn{4}{|c|}{ This work } & \multicolumn{4}{|c|}{ Previous work ${ }^{a}$} \\
\hline & \multicolumn{2}{|c|}{ AS } & \multicolumn{2}{|c|}{ CS } & \multicolumn{2}{|c|}{ AS } & \multicolumn{2}{|c|}{ CS } \\
\hline & Amount (g/L) & Yield (\%) & Amount (g /L) & Yield (\%) & Amount (g/L) & Yield (\%) & Amount (g/L) & Yield (\%) \\
\hline$\alpha-C D$ & $6.40 \pm 0.26^{b}$ & 12.81 & $3.85 \pm 0.085$ & 7.70 & $6.46 \pm 0.071$ & 9.23 & $5.88 \pm 0.094$ & 8.4 \\
\hline$\beta-C D$ & $8.97 \pm 0.36$ & 17.94 & $5.39 \pm 0.11$ & 10.78 & $6.13 \pm 0.092$ & 8.76 & $2.84 \pm 0.059$ & 4.06 \\
\hline$\gamma-C D$ & $4.98 \pm 0.20$ & 9.92 & $2.99 \pm 0.06$ & 5.99 & $2.98 \pm 0.084$ & 4.25 & $1.47 \pm 10.19$ & 2.1 \\
\hline$\sum C D$ & 20.35 & 40.73 & 12.23 & 24.48 & 15.57 & 22.24 & 10.19 & 14.56 \\
\hline
\end{tabular}

aIn either work, AS was used as substrate for CGTase to synthetize enzymatically CDs and CS was used as control.

${ }^{b}$ Data are mean \pm standard deviation of three replicates.

was $114 \mathrm{kDa}$ (Urban et al., 2012). The purified CGTase showed activity at pHs between 3.0 and 10.0, however, its optimum $\mathrm{pH}$ was 8.0 using both AS and CS as substrate. There is widespread agreement on the optima $\mathrm{pH}$ values (7-12) reported for purified CGTases from Bacillus sp. and B. megaterium. Most CGTases exhibit optimum $\mathrm{pH}$ ranging from 5.0 to 8.0. However, the CGTase with the highest $\mathrm{pH}$ (10.0) was reported for the one produced by Brevibacterium sp. no. 9605 (Mori et al., 1974; Martínez-Mora et al., 2012). CGTase from B. agaradhaerens LS$3 \mathrm{C}$, possesses the widest $\mathrm{pH}$ range for stability, specifically $\mathrm{pH}$ 5.4-11.0 (Gastón et al., 2009). With respect to the temperature, in this work was observed CGTase activity in all temperatures assayed and the optimum was $50^{\circ} \mathrm{C}$, however, previous studies showed that CGTase activity occurs between 23 and $110^{\circ} \mathrm{C}$. The enzyme remained active in the tested temperature range from 30 to $70^{\circ} \mathrm{C}$ (More et al., 2012). Previous reports have shown that the $\mathrm{Km}$ values of CGTase from various Bacillus using soluble CS, are in the range from 0.05 to $15.54 \mathrm{mM}$ (More et al., 2012). This shows that the partially purified CGTase has a relatively high affinity for AS. Kelly et al. (2008) reported values ranging from $3.0 \times 10^{-3} / \mathrm{s}$ to $329 / \mathrm{s}$ for CGTases produced with CS as carbon source. The CGTase from B. megaterium, using AS as substrate in this work, is in agreement with the Kcat values published elsewhere (Shahrazi et al., 2013; Usharani et al., 2014). CDs are produced by the catalytic action of CGTase through an intramolecular transglycosylation reaction. The enzyme displays its cyclic action on substrates with $\alpha$-1,4-glycosyl chains such as starch, amylose, amylopectin, dextrins and glycogen. However, starch is the most commonly used material for CD production (Zhekova et al., 2009). Nevertheless, a complete conversion of starch to $\mathrm{CD}$ is not likely, even at optimal reaction conditions. According to published literature, the main limiting factors are inhibition of CGTase by CD and maltoologosaccharides, coupled activity of the enzyme, inability of CGTase to act on $\alpha-1,4$ linkages of starch and the low molecular mass of the substrate. All known CGTase produces a mixture of $\alpha-, \beta$-, and $\gamma$-CDs at different ratios. They have been further classified into $\alpha$-, $\beta$ , and $\gamma$-CGTases according to their main cyclodextrin products during the initial phase of the reaction (Urban et al., 2012). B. megaterium produces all three types of CDs, but the predominant product is $\beta$-CD (Pishtiyski et al., 2008). Urban et al. (2012) also observed a greater total CDs production using AS than
CS, but the CGTase used in our study was produced by $B$. megaterium using AS as carbon source. Moreover, the CGTase of this study mainly produced $\beta$-CD (17.94\%) in comparison to that reported by Urban et al. (2012) which was $8.76 \%$. It was also observed that total CDs yield (AS $=40.73 \%$; CS $=$ $24.48 \%$ ) in this study was roughly twice as much as that obtained previously for AS (22.24\%) and CS (14.56\%) by Urban et al. (2012). The previous procedure does not produce a good yield of $\gamma$-CD. For this purpose, a CGTase that predominantly produces $\gamma$-CD can be used (Li et al., 2007). Higher amylopectin content, higher dispersibility, and higher starch-granule susceptibility to amylases can facilitate the CGTase activity to synthesize CDs using the amaranth starch as substrate (Tomita et al., 1981). The influence of various substrates including starchs from corn, potato, sago, rice and tapioca has been assessed. Potato starch seems to give the highest conversion into CDs. Additionally, CDs yield was about 3-fold higher when using gelatinized potato starch in comparison to raw starch (Ibrahim et al., 2011).

\section{CONCLUSION}

The amaranth starch displays a higher amylopectin content, higher dispersibility, and higher starch-granule susceptibility to amylases activity than those properties displayed by corn starch. These features can facilitate the CGTase production by a SmF as well as the synthesis of cyclodextrins when the partially purified CGTase is used in the enzymatic reaction. Therefore, amaranth starch might be a good alternative not only to obtain CGTase, but also to produce a higher $\alpha$-, $\beta$-, and $\gamma$-cyclodextrins content than that afforded by corn starch. The use of CDs in the pharmaceutical and food industries is limited by high costs. Thus, many efforts have been directed to produce CDs by continuous processes in substitution of the batch process, and immobilized cells have shown higher productivity when used in continuous processes (Moriwaki et al., 2014). Therefore, the high costs could decrease by applying this technique.

\section{AUTHOR CONTRIBUTIONS}

This work was carried out in collaboration between all authors. Author JS designed the study, contributed reagents/materials 
and supervised work in all its aspects. Author MA carried out trials and prepared the protocol. Author EP managed the literature searches. Authors ED and RP performed the statistical analysis and also supervised this study. Author GD followed and supervised the fermentations performed in this proyect.

\section{REFERENCES}

AOAC (2000). Association Official Analytical Chemists. Official Methods of Analyses, 17th Edn. Washington, DC: Association of Official Analytical Chemists.

Ahmed, E. M., and El-Refai, H. A. (2010). Cyclodextrin glucosyltransferase production by Bacillus megaterium NCR: evaluation and optimization of culture conditions using factorial design. Indian J. Microbiol. 50, 303-308. doi: 10.1007/s12088-010-0009-x

Anselmi, C., Centini, M., Maggiore, M., Gaggelli, M. A., Buonocore, A., Beretta, G., et al. (2008). Non-covalent inclusion of ferulic acid with $\alpha$-cyclodextrin improves photo-stability and delivery: NRM and modelling studies. J. Pharm. Biomed. Analysis 46, 645-652. doi: 10.1016/j.jpba.2007.11.037

Cheirsilp, B., Kitcha, S., and Maneerat, S. (2010). Kinetic characteristics of -cyclodextrin production by cyclodextrin glycosyltransferase from newly isolated Bacillus sp. C26. Electron. J. Biotechnol. 13, 4-5. doi: 10.2225/vol13issue4-fulltext-6

Costa, H., Gastón, J. R., Lara, J., Martinez, C. O., Moriwaki, C., Matioli, G., et al. (2015). Cyclodextrin glycosyltransferase production by free cells of Bacillus circulans DF 9R in batch fermentation and by immobilized cells in a semi-continuous process. Bioprocess Biosyst. Eng. 38, 1055-1063. doi: 10.1007/s00449-014-1347-6

de Freitas, T. L. D., Monti, R., and Contiero, J. (2004). Production of CGTase by a Bacillus alkalophilic CGII strain isolated from wastewater of a manioc flour industry. Braz. J. Microbiol. 35, 255-260. doi: 10.1590/S151783822004000200015

Elbaz, A. F., Sobhi, A., and ElMekawy, A. (2015). Purification and characterizationof cyclocextrin $\beta$-glucanotransferase from novel alkalophilic bacilli. Bioprocess Biosyst. Eng. 38, 767-776. doi: 10.1007/s00449-014-1318-y

Gastón, J. A. R., Szerman, N., Costa, H., Krymkiewicz, N., and Ferrarotti, S. A. (2009). Cyclodextrin glycosyltransferase from Bacillus circulans DF 9R: activity and kinetic studies. Enzyme Microb. Technol. 45, 36-41. doi: 10.1016/j.enzmictec.2009.04.002

Gheetha, R., and More, S. S. (2010). Isolation and characterization of cyclodextrin glucanotransferase from soil bacterium. Res. J. Biol. Sci. 5, 699-707. doi: 10.3923/ribsci.2010.699.707

Han, R., Li, J., Shin, H. D., Chen, R. R., Du, G., Liu, L., et al. (2014). Recent advances in discovery, heterologous expression, and molecular engineering of cyclodextrin glycosyltransferase for versatile applications. Biotechnol. Adv. 32, 415-428. doi: 10.1016/j.biotechadv.2013.12.004

Holm, J., Björck, I., Drews, A., and Asp, N. G. (1986). A rapid method for the analysis of starch. Starch 38, 224-226. doi: 10.1002/star.19860380704

Ibrahim, A. S. S., El-Tayeb, M. A., Elbadawi, Y. B., and Al-Salamah, A. A. (2011). Effects of substrates and reaction conditions on production of cyclodextrins using cyclodextrin glucanotransferase from newly isolated Bacillus agaradhaerens KSU-A11. Ejbiotechnology 14. doi: 10.2225/vol14issue5-fulltext-4

Ivanova, V. (2010). Immobilization of cyclodextrin glucanotransferase from Paenibacillus macerans ATCC 8244 on magnetic carriers and production of cyclodextrins. Biotechnol. Biotec. Equip. 24, 516-528. doi: $10.1080 / 13102818.2010 .10817893$

Kelly, R., Leemhuis, H., Rozeboom, H., van Oosterwijk, N., Dijkstra, B., and Dijkhuizen, L. (2008). Elimination of competing hydrolysis and coupling side reactions of a cyclodextrin glucanotransferase by directed evolution. Biochem. J. 413, 517-525. doi: 10.1042/BJ20080353

Kitahata, S., Tsuyama, N., and Okada, S. (1974). Purification and some properties of cyclodextrin glycosyltransferase from a strain of Bacillus species. Agr. Biol. Chem. 38, 387-393. doi: 10.1080/00021369.1974. 10861152

\section{ACKNOWLEDGMENTS}

We are grateful to Prof. Abraham Avendaño-Martínez for proofreading and translating the manuscript. MA was supported by a CONACYT scholarship (No. 330389).

Kong, X., Corke, H., and Bertoft, E. (2009). Fine structure characterization of amylopectins from grain amaranth starch. Carbohydr. Res. 344, 1701-1708. doi: 10.1016/j.carres.2009.05.032

Kurkov, S. V., and Loftsson, T. (2013). Cyclodextrins. Int. J. Pharm. 453, 167-180. doi: 10.1016/j.ijpharm.2012.06.055

Li, Z., Wang, M., Wang, F., Gu, Z., Du, G., Wu, J., et al. (2007). $\gamma$-Cyclodextrin: a review on enzymatic production and applications. Appl. Microbiol. Biotechnol. 77, 245-255. doi: 10.1007/s00253-007-1166-7

Mäkelä, M. J., Paavilainen, S. K., and Korpela, T. K. (1990). Growth dynamics of cyclomaltodextrin glucanotransferase producing Bacillus circulans var. alkalophilus. Can. J. Microbiol. 36, 176-182. doi: 10.1139/ m90-031

Martínez-Mora, M., Hernández-Sánchez, K., Villalonga-Santana, R., Pérez-Rojas, A., Ramírez, H. L., and Torres-Labandeira, J. J. (2012). Partial purification and properties of cyclodextrin glycosiltransferase (CGTase) from alkalophilic Bacillus species. SpringerPlus 1, 1-6. doi: 10.1186/2193-1801-1-61

More, S. S., Niraja, R., Evelyn, C., Byadgi, A. M., Shwetha, V., and Mangaraj, S. D. (2012). Isolation, purification and biochemical characterization of CGTase from Bacillus halodurans. Croatian J. Food Technol. Biotechnol. Nut. 7, 90-97.

Mori, S., Hirose, S., Oya, T., and Kitahata, S. (1974). Purification and properties of cyclodextrin glucanotrasferase from Brevibacterium sp. no. 9605. Biosci. Biotechnol. Biochem. 58, 1968-1972. doi: 10.1271/bbb.58.1968

Moriwaki, C., Mangolim, C. S., Ruiz, G. B., de Morais, G. R., Baesso, M. L., and Matioli, G. (2014). Biosynthesis of CGTase by immobilized alkalophilic bacilli and crystallization of beta-cyclodextrin: effective techniques to investigate cell immobilization and the production of cyclodextrins. Biochem. Eng. J. 83, 22-32. doi: 10.1016/j.bej.2013.12.004

Ng, H. S., Ooi, C. W., Mokhtar, M. N., Show, P. L., Ariff, A., Tan, J. S., et al. (2013). Extractive bioconversion of cyclodextrins by Bacillus cereus cyclodextrin glycosyltransferase in aqueous two-phase system. Bioresour. Technol. 142, 723-726. doi: 10.1016/j.biortech.2013.05.087

Pishtiyski, I., Popova, V., and Zhekova, B. (2008). Characterization of cyclodextrin glucanotransferase produced by Bacillus megaterium. Appl. Biochem. Biotechnol. 144, 263-272. doi: 10.1007/s12010-007-8009-y

Rakmai, J., and Cheirsilp, B. (2016). Continuous production of $\beta$-cyclodextrin by cyclodextrin glycosyltransferase immobilized in mixed gel beads: comparative study in continuous stirred tank reactor and packed bed reactor. Biochem. Eng. J. 105(Part A), 107-113. doi: 10.1016/j.bej.2015.09.011

Sá Couto, A., Salústio, P., and Cabral-Marques, H. (2015). "Cyclodextrins" in Polysaccharides Bioactivity and Biotechnology eds K. G. Ramawat, J.-M. Mérillon (Cham: Springer International Publishing), 263-265.

Savergave, L. S., Dhule, S. S., Jogdand, V. V., Nene, S. N., and Gadre, R. V. (2008). Production and single step purification of cyclodextrin glycosyltransferase from alkalophilic Bacillus firmus by ion exchange chromatography. Biochem. Eng. J. 39, 510-515. doi: 10.1016/j.bej.2007.09.020

Shahrazi, S., Saallah, S., Mokhtar, M. N., Baharuddin, A. S., and Yunos, K. F. M. (2013). Dynamic mathematical modelling of reaction kinetics for cyclodextrins production from different starch sources using Bacillus macerans cyclodextrin glucanotransferase. Am. J. Biochem. Biotechnol. 9, 195-205. doi: 10.3844/ajbbsp.2013.195.205

Sivakumar, N., and Shakilabanu, S. (2013). Production of cyclodextrin glycosyl transferase by Bacillus megaterium. Int. J. Curr. Microbiol. Appl. Sci. 2, 44-55.

Sukiminderjit, K., Simranjeet, K., and Kirandeep, K. (2014). Studies on $\beta$ cyclodextrin productos from CGTase producing bacteria and its effect on drug solubility. Int. J. Pharm. Pharmal. 6, 383-387.

Suntinanalert, P., Petmaneechote, J., Damnian, N., and Hutadilok, T. N. (1997). Purification and properties of cyclodextrin glycosyltransferase (CGTase) from an alkaline-tolerant Bacillus sp. PS304. J. Sci. Soc. Thail. 23, 381-388. doi: 10.2306/scienceasia1513-1874.1997.23.381 
Tomita, Y., Sugimoto, Y., Sakamoto, S., and Fuwa, H. (1981). Some properties of starches of grain amaranths and several millets. J. Nutr. Sci. Vitaminol (Tokyo). 27, 471-484. doi: 10.3177/jnsv.27.471

Urban, M., Beran, M., Adamek, L., Drahorád, J., Molík, P., and Matušová, K. (2012). Cyclodextrin production from amaranth starch by cyclodextrin glycosyltransferase produced by Paenibacillus macerans CCM 2012. Czech. J. Food Sci. 30, 15-20.

Usharani, L., Prasad, T., Sundar, S., Dhananjaya, K., and Mallesha, H. (2014). Comparative study of cyclodextrin production from the CGTase producing novel strains characterization and hostguest complex formation J. Drug Deliv. Ther. 4, 77-81.

Villarreal, M. E., Ribotta, P. D., and Iturriaga, L. B. (2013). Comparing methods for extracting amaranthus starch and the properties of the isolated starches. LWT-Food Sci. Technol. 51, 441-447. doi: 10.1016/j.lwt.20 12.11.009

Zhekova, B., Dobrev, G., Stanchev, V., and Pishtiyski, I. (2009). Approaches for yield increase of $\beta$-cyclodextrin formed by cyclodextrin glucanotransferase from Bacillus megaterium. World J. Microbiol. Biotechnol. 25, 1043-1049. doi: 10.1007/s11274-009-9985-6

Zhou, J., Liu, H., Du, G., Li, J., and Chen, J. (2012). Production of $\alpha$-cyclodextrin glycosyltransferase in Bacillus megaterium MS941 by systematic codon usage optimization. J. Agric. Food Chem. 60, 10285-10292. doi: 10.1021/jf302819h

Conflict of Interest Statement: The authors declare that the research was conducted in the absence of any commercial or financial relationships that could be construed as a potential conflict of interest.

Copyright (C) 2016 Arce-Vázquez, Ponce-Alquicira, Delgado-Fornué, Pedroza-Islas, Díaz-Godinez and Soriano-Santos. This is an open-access article distributed under the terms of the Creative Commons Attribution License (CC BY). The use, distribution or reproduction in other forums is permitted, provided the original author(s) or licensor are credited and that the original publication in this journal is cited, in accordance with accepted academic practice. No use, distribution or reproduction is permitted which does not comply with these terms. 